\title{
Long-Term Structural Valve Degeneration in Cryopreserved Mitral and Aortic Homograft: Is Pregnancy a Factor?
}

\author{
Francesco Nappi*, Cristiano Spadaccio, Massimo Chello, Mario Lusini, Cristophe Acar \\ Department of Cardiac Surgery, Centre Cardiologique du Nord, St. Denis, France \\ Email: ${ }^{*}$ francesconappi2@gmail.com
}

Received 29 March 2014; revised 5 May 2014; accepted 12 May 2014

Copyright (C) 2014 by authors and Scientific Research Publishing Inc. This work is licensed under the Creative Commons Attribution International License (CC BY). http://creativecommons.org/licenses/by/4.0/

(c) (i) Open Access

\section{Abstract}

Objective: This study reports the outcomes of the cryopreserved mitral homograft in 119 patients prospectively followed with clinical, echocardiographic and structural valve deterioration assessments. Methods: 119 patients undergoing mitral and aortic homograft implantation. Patient's causes of mitral disease were: rheumatic disease $(n=75)$, endocarditis $(n=37)$ and others $(n=7)$. There were 40 partial homografts and 88 total homografts. Mitro-aortic homograft valve replacement was performed in 29 cases. Results: Mean follow-up was $9.8 \pm 6.3$ years (up to 19.2 yrs). There were 7 early ( $<3$ months) and 16 late deaths. There have been 9 early ( $<3$ months) and 35 late reoperations. Nine patients had an endocarditis and 6 had ischemic/haemorrhagic event. As compared to baseline, follow-up echography showed progression of MR grade (from 0.4 to $1.3 \mathrm{p}<$ 0.001 ) with stenosis (elevated gradient: from 3.9 to $7.0 \mathrm{mmHg} p<0.001$ and decreased valve area: from 2.3 to $1.7 \mathrm{~cm}^{2} \mathrm{p}<\mathbf{0 . 0 0 1}$ ). Proportion of patients free from structural valve deterioration (SVD) was $90 \%, 76 \%$ and $65 \%$ at 5 years, 10 years and 15 years respectively. Pregnancy and endocarditis etiology were found to be the main determinants of SVD. Stenosis related to SVD was more pronounced for age $<40$ years and ring size $30 \mathrm{~mm}$. Mitro aortic homograft valve replacement was the preferred choice in complex infective endocarditis. Pathological analysis of the explanted homografts almost invariably showed dense fibrosis with calcification and no cellularity. Conclusion: Mitral homografting could be accomplished with early echographic results similar to those of valve repair. SVD produced mixed stenosis with insufficiency and its incidence was comparable to that of bioprostheses SVD. An improvement in the preservation mode of valvular homografts is warranted. Double cryopreserved homograft implantation in the context of infective endocarditis might be an effective strategy especially if the mitro-aortic continuity is involved. However, a par-

*Corresponding author. 
ticular attention should be paid to in women in childbearing age because pregnancy might accelerate structural degeneration of the cryopreserved homografts.

\author{
Keywords
}

\author{
Mitral, Homograft, Cryopreserved
}

\title{
1. Introduction
}

Despite the controversial and different choice of surgeons, the allogenous transplantation of the mitral valve has remained an open question [1]. In the beginning of the nineties isolated cases of complete mitral homograft replacement [2] were reported including the description from our group of an original technique based on a side-to-side suturing of the homograft papillary muscles with multiple interrupted stitches together with prosthetic ring implantation [3]. In 1996 the technique applied in a series of 43 patients proved to be safe and reproducible [4] and the eight years follow-up results were further reported by our group [5]. Also, Doty et al. described the mid-term clinical and echographic results (mean 4.3 years) in a series of 104 patients [6]. The aim of the present study was to evaluate the durability of the cryopreserved mitral homograft valve over a period extending for up to 19 years focusing on structural valve deterioration and to evaluate the clinical outcomes of double homograft implantation in case of complex endocarditis involving the mitro-aortic continuity.

\section{Methods}

\subsection{Patients}

From February 1993 to May 2008, 119 patients (female: $n=72$, male: $n=47$ ) underwent mitral valve replacement with a cryopreserved homograft in a non-academic tertiary referral hospital. The mean age was $41.2 \pm 18$ years (10 to 73 years) with 13 patients aged less than 18 years. The aetiology of mitral valve disease was: rheumatic valve disease $(n=75)$, bacterial endocarditis $(n=37)$ including 5 cases involving a previously diseased mitral valve (rheumatic valve disease: $n=3$, Barlow disease: $n=2$ ), autoimmune disorder $(n=4)$ (systemic lupus: $\mathrm{n}=2$, primary antiphos-pholipid syndrome: $\mathrm{n}=1$, juvenile polyarthritis: $\mathrm{n}=1)$, marasmic endocarditis $(\mathrm{n}=$ 1), Barlow disease $(n=1)$ and congenital stenosis $(n=1) .23$ patients were in chronic atrial fibrillation while the remnant 105 showed no EKG alterations. 40\% of the patients with acute articular rheumatism were from the New Caledonia and Tahiti and were of Polynesian race, $40 \%$ were white Eurasians and 20\% were from the Antilles. Twenty-eight patients had priorly undergone mitral valve operations: repair $(n=23)$ or replacement $(n=$ 5). The motivation and rationale to select a homograft was related to age (less than 18 years) in 11 cases, childbearing age in 38) presence of absolute contraindication to oral anticoagulation in 50 and endocarditis in 46 patients.

\subsection{Surgical Technique}

The technical details of mitral homograft insertion have been previously described [6]. Surgical stategy was based on the extent of valve lesions. Partial homograft replacement was performed in 40 cases using in 10 cases an anterior leaflet patch or a mitral hemi-valve with reimplantation of the corresponding papillary muscle in 30 patients. Subjects with endocarditis preferentially underwent partial homograft replacement (16/24). Complete homograft replacement was performed in 88 patients. All patients underwent prosthetic ring annuloplasty with either a Carpentier Physio ring $(n=72)$ or a flexible Duran ring $(n=34)$. Ring size was reported by the intercommissural distance given by the Carpentier obturator or the Duran obturator $\pm 2 \mathrm{~mm}$. Mean ring size was 31.4 $\pm 1.7 \mathrm{~mm}$ (28 to $36 \mathrm{~mm}$ ). Due to smaller body size in the pediatric group, ring size in patients below 40 years of age was smaller than in older patients $\left(31.1 \pm 1.8\right.$ versus $\left.31.7 \pm 1.7 \mathrm{~cm}^{2} \mathrm{p}=0.04\right)$. Likewise, ring size was smaller in complete than in partial homografts $\left(31.2 \pm 1.7\right.$ versus $\left.31.8 \pm 1.7 \mathrm{~cm}^{2} \mathrm{p}=0.01\right)$. Combined procedures included aortic valve repair in 5 patients, aortic valve replacement with a homograft in 29, tricuspid valve annuloplasty in 7 , or tricuspid valve replacement with a mitral homograft in 2, pulmonary vein isolation in 4 cases and coronary artery bypass in 1 patient. In the complex endocarditis the homograft root replacement has 
become the technique of choice when the abscesses can be either localized to the septum, to the aortomitral triangle or else or they can destroy the whole annulus leading to an aorto-ventricular dehiscence as often seen in prosthetic valve endocarditis.

\subsection{Clinical Follow-Up}

Clinical follow-up was achieved by routine visits and physical examination or by phone interview with referring cardiologist, general practitioner or patient self. Data collection was performed at fixed time intervals (approximately 6 years) and an additional cross sectional analysis was retrospectively performed over the second semester of the year 2012.

\subsection{Statistical Analysis}

Descriptive data for continuous variables were presented as means with standard deviation. Patients groups were compared by chi-square test for categorical values and Student's t test for continuous variables. Differences were considered to be significant when $\mathrm{p}<0.05$. Survival, freedom from reoperation and freedom from structural deterioration were estimated according to the Kaplan-Meier method. When structural valve deterioration was detected by echocardiography, the date of the exam was used for constructing the Kaplan-Meier curve.

\section{Results}

Follow-up was $96.2 \%$ complete (8 patients lost to follow-up). Mean duration of the observation period was 10.8 \pm 6.7 years (from 0.4 to 18.8 years).

\subsection{Survival}

Perioperative early deaths ( $<3$ months) were registered in 8 cases (5.7\%), while 15 other patients died subsequently. Cardiac deaths included congestive heart failure $(n=4)$, pulmonary embolus $(n=1)$ and death at reoperation $(n=3)$. Non-cardiac causes of mortality regarded cancer $(n=9)$ (laryngeal $n=1$, lung $n=2$, digestive $\mathrm{n}=4$, blood $\mathrm{n}=1$ and urogenital $\mathrm{n}=1$ carcinoma), HIV-related infection $(\mathrm{n}=1)$, trauma with cerebral haemorrhage $(n=1)$ and degenerative neuropathy $(n=1)$. Survival according to the Kaplan Meier estimate was $88 \%, 85 \%$ and $80 \%$ at 5 years, 10 years and 15 years respectively (Figure 1 ).

\subsection{Reoperation}

There were 9 early reoperations within 3 months due to mitral homograft failure. Causes were related to technical issues and included restriction due to improper papillary muscle positioning in 5 cases, leaflet suture dehiscence in 2 cases and chordal rupture due to erosion by the suture material in 2 patients, as described in the litterature [6] [7]. Overall freedom from reoperation was 67\% with 34 late reoperations ( $>3$ months) after a mean period of 8.6 years (1.3 to 14.9 years). Indications for late reoperations included in 23 cases degeneration of the mitral homograft, bacterial endocarditis in 8 patients and aortic valve disease in 3 cases. Kaplan Meier freedom from reoperation was 88\%, 80\% and 64\% at 5 years, 10 years and 15 years respectively (Figure 1). Non endocarditis etiology was found to be associated to the risk of reoperation $(\mathrm{P}=0.004)$. Other candidates determinants for reoperation were found to be age (below versus over 40 years), homograft technique (total versus partial homograft), prosthetic ring size (equal to or less than $30 \mathrm{~mm}$ versus larger size), associated aortic valve surgery and pregnancy. However, these variables failed to reach statistical significance in determining reoperation (Table $\mathbf{1}$ ).

\subsection{Technique and Results}

Reoperation following mitral homograft replacement did not pose particular technical challenges. The mitral homograft could be safely replaced in all cases except in one patient, who required aortic valve replacement, in which no dysfunction of an anterior leaflet homograft patch could be detected. Prophylactic replacement of a mildly dysfunctioning mitral homograft was performed in a patient reoperated at 10 years for aortic valve dysfunction. We always proceeded at prosthetic ring removal at the beginning of the procedure, then the whole mitral homograft valve was excised. According to the extent of calcifications, it was seldom possible to retain basal 


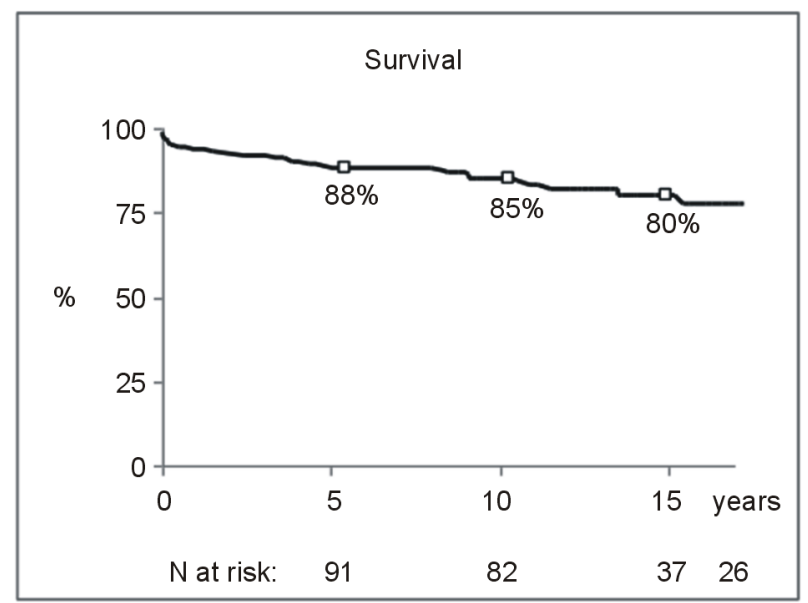

(a)

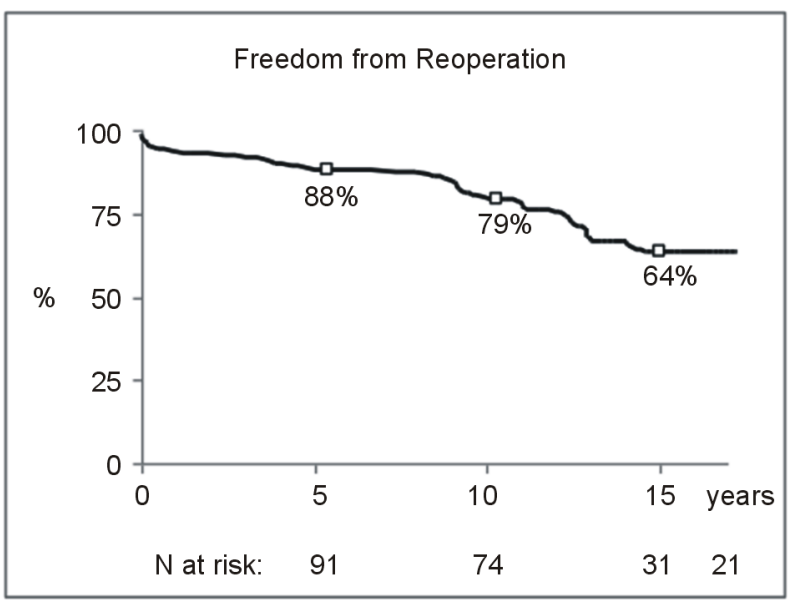

(b)

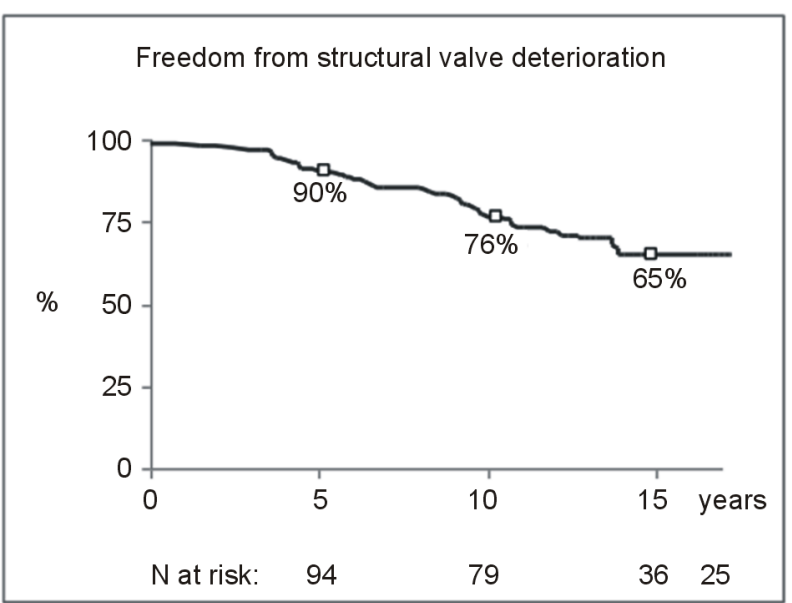

(c)

Figure 1. Kaplan Meier estimate of survival, freedom from reoperation and freedom from structural valve deterioration in 119 patients with a cryopreserved mitral homograft valve.

chordae of the homograft. Mitral valve replacement was performed with a mechanical prosthesis in 20 cases and a bioprosthesis in 14 cases. Associated aortic valve replacement was realized in 7 cases and was due to repair 
failure in 2 cases, homograft degeneration in 3 patients and progression of rheumatic disease in 2 cases. Tricuspid valve surgery was required in 13 cases: annuloplasty $(n=12)$ and replacement with a bioprosthesis $(n=1)$. The need for tricuspid valve surgery was found to be greater in reoperations than at primary surgery $(\mathrm{p}<0.001)$.

Also mortality at reoperation was $8.6 \%$ not statistically higher than that of the first operation $(p=0.39$ ). Causes of death included uncontrolled sepsis secondary to endocarditis, bleeding at sternal reentry and left ventricular dysfunction related to technical problems in replacing a calcified aortic homograft root.

\subsection{Echocardiographic Study}

Baseline echocardiography was performed immediately after the operation at the time of discharge. Follow-up echocardiography was obtained at the latest periodical exam or immediately prior to redo surgery. Mitral valve regurgitation was graded according to jet extension. Transvalvular gradient was measured by Doppler and surface valve area was calculated according to the Hattle formula.

Echocardiography at discharge showed grade 3 or 4 mitral regurgitation in 5 patients and they underwent immediate reoperation. In the remaining cases, echography at discharge showed a normal mitral valve function (Table 2). Left atrial diameter and left ventricular diameter were $48.0 \pm 12 \mathrm{~mm}$ and $50.3 \pm 6.7 \mathrm{~mm}$ respectively. Left ventricular ejection fraction was $60.0 \% \pm 8 \%$. At discharge we could not find differences as far as the age (>40 vs. $<40$ years) type of homograft (partial versus total homograft) and ring size (equal to or less than $30 \mathrm{~mm}$ versus ring size $>30 \mathrm{~mm}$ ) are concerned.

Echocardiography follow-up was obtained in all cases after a mean period of $7.6 \pm 4.1$ years (0.3 to 16.2 years). A variable degree of leaflet thickening together with a progressively worsening regurgitant and stenotic

Table 1. Determinants of reoperation.

\begin{tabular}{|c|c|c|c|}
\hline Variable & & n (\%) & $P$ value \\
\hline \multirow{2}{*}{ Age } & & 20/61 (32.78\%) & \multirow{2}{*}{$\begin{array}{c}\mathrm{p}=0.42 \\
\mathrm{NS}\end{array}$} \\
\hline & $>40 \mathrm{yrs}$ & 15/58 (25.86\%) & \\
\hline \multirow{2}{*}{ Homograft technique } & Total & 26/79 (32.9\%) & \multirow{2}{*}{$\begin{array}{c}\mathrm{p}=0.29 \\
\mathrm{NS}\end{array}$} \\
\hline & Partial & 9/40 (22.5\%) & \\
\hline \multirow{2}{*}{ Ring size } & $\leq 30 \mathrm{~mm}$ & 18/49 (36.7\%) & \multirow{2}{*}{$\begin{array}{c}\mathrm{p}=0.45 \\
\mathrm{NS}\end{array}$} \\
\hline & $>\mathbf{3 0} \mathbf{m m}$ & 17/57 (29.8\%) & \\
\hline \multirow{2}{*}{ Associated aortic surgery } & YES & $7 / 28$ (25\%) & \multirow{2}{*}{$\begin{array}{c}\mathrm{p}=0.64 \\
\mathrm{NS}\end{array}$} \\
\hline & No & 28/91 (30.8\%) & \\
\hline \multirow{2}{*}{ Primary endocarditis } & YES & 6/37 (30.8\%) & \multirow{2}{*}{$\mathrm{p}=0.004$} \\
\hline & NO & 29/82 (35.3\%) & \\
\hline \multirow{2}{*}{ Pregnancy } & YES & 3/9 (33.3\%) & \multirow{2}{*}{$\begin{array}{c}\mathrm{p}=0.98 \\
\mathrm{NS}\end{array}$} \\
\hline & NO & 32/97 (40.0\%) & \\
\hline
\end{tabular}

Table 2. Echocardiographic evaluation of mitral homograft valve function.

\begin{tabular}{|c|c|c|c|c|c|c|c|}
\hline \multicolumn{2}{|c|}{ Echocardiography } & \multicolumn{2}{|c|}{ MRgrade } & \multicolumn{2}{|c|}{ Mean gradient (mmHg) } & \multicolumn{2}{|c|}{ Valve area $\left(\mathrm{cm}^{2}\right)$} \\
\hline \multicolumn{2}{|c|}{ At discharge } & $0.4 \pm 0.5$ & \multirow{2}{*}{$\mathrm{p}<0.001$} & $3.9 \pm 1.5$ & \multirow{2}{*}{$\mathrm{p}<0.001$} & $2.3 \pm 0.5$ & \multirow{2}{*}{$\mathrm{p}<0.001$} \\
\hline \multicolumn{2}{|c|}{ At follow-up } & $1.3 \pm 1.2$ & & $7.0 \pm 3.9$ & & $1.7 \pm 0.6$ & \\
\hline \multirow{2}{*}{ Age } & $<40$ yrs & $1.3 \pm 1.3$ & \multirow{2}{*}{$\begin{array}{c}p=0.49 \\
N S\end{array}$} & $8.1 \pm 4.2$ & \multirow{2}{*}{$\mathrm{p}<0.001$} & $1.7 \pm 0.6$ & \multirow{2}{*}{$\mathrm{p}=0.03$} \\
\hline & $>40$ yrs & $1.3 \pm 1.2$ & & $5.4 \pm 2.4$ & & $1.9 \pm 0.4$ & \\
\hline \multirow{2}{*}{$\begin{array}{c}\text { Homograft } \\
\text { Technique }\end{array}$} & Total & $1.4 \pm 1.2$ & \multirow{2}{*}{$\begin{array}{c}p=0.07 \\
\text { NS }\end{array}$} & $7.7 \pm 4.1$ & \multirow{2}{*}{$p=0.004$} & $1.7 \pm 0.6$ & \multirow{2}{*}{$p=0.02$} \\
\hline & Partial & $1.4 \pm 1.3$ & & $5.6 \pm 2.6$ & & $1.9 \pm 0.5$ & \\
\hline \multirow{2}{*}{ Ring size } & $\leq 30 \mathrm{~mm}$ & $1.4 \pm 1.3$ & \multirow{2}{*}{$\begin{array}{c}\mathrm{p}=0.59 \\
\mathrm{NS}\end{array}$} & $8.2 \pm 4.1$ & \multirow{2}{*}{$p=0.002$} & $1.6 \pm 0.5$ & \multirow{2}{*}{$\mathrm{p}=0.002$} \\
\hline & $>30 \mathrm{~mm}$ & $1.2 \pm 1.2$ & & $5.9 \pm 3.1$ & & $1.9 \pm 0.6$ & \\
\hline
\end{tabular}


process could be detected. When compared to baseline data at discharge, the degree of mitral regurgitation was significantly increased (Table 2). Similarly, transvalvular gradient was higher and surface valve area was reduced (Table 1). An increase in mean systolic pulmonary artery pressure was detected $(37.6 \pm 9.9 \mathrm{mmHg})(\mathrm{p}=$ $0.001)$. However, left heart chambers size remained unchanged (atrial diameter: $49.0 \pm 8.4) \mathrm{mm}(\mathrm{p}=0.54)$; ventricular diastolic diameter: $50.8 \pm 7.3 \mathrm{~mm}(\mathrm{p}=0.54)$ as well as ejection fraction $(59.1 \% \pm 8.6 \%)(\mathrm{p}=0.52)$.

We could not finda maindeterminant contributing to mitral homograft regurgitation (Table 2). In contrast, the onset of homograft stenosis was markedly accelerated with a higher gradient and a smaller valve area in: age below 40 years versus older patients, total versus partial homograft and ring size equal or less than $30 \mathrm{~mm}$ compared to larger ring sizes (Table 2).

\subsection{Structural Valve Deterioration}

Structural deterioration was detected at explantation during reoperation in 33 cases (Figures 2-3). The majority of mitral homografts showed some degree of leaflet thickening at echocardiography. In 10 other cases structural deterioration was demonstrated by echocardiography showing gross thickening/calcification together with severe homograft dysfunction. These patients were not reoperated as either asymptomatic, or not giving consent to surgery or presented a contraindication for surgery due to comorbidities. Valve insufficiency was reported in 6 cases, predominant stenosis in 12 cases while combined disease 15 patients. No statistical significant difference could be found in the occurrence of SVD among patients receiving a total or a partial homograft. However, non-endocarditis etiology ( $p=0.02)$ and pregnancy $(p=0.016$ versus no pregnancy) were found to be significantly associated to SVD. Pregnancy significantly predicted valve degeneration (Table 3). Age, ring size and associated aortic valve surgery did not significantly influence structural valve deterioration. Freedom from structural mitral homograft deterioration according to the Kaplan Meier estimate was $90 \%, 76 \%$ and $65 \%$ at 5 years, 10 years and 15 years respectively (Figure 1 ).

\section{Discussion}

Over the past decade, many isolated cases of mitral valve homograft particularly in endocarditis [8] [9] or in children [10] as well as small series with short term follow-up [11]-[13] have been published. Intermediate term results (5 years) have been a matter of controversy [14] [15].

Early valve failure as observed during the learning phase in few mitral homografts phase was related to the surgical technique and has been addressed in previous reports [5] [6]. The present study was design to assess late reoperation focusing on structural valve deterioration and to evaluate the clinical outcomes of double homograft implantations in case of complex endocarditis involving the mitro-aortic continuity. At 15 years, one third of patients were reoperated.

The most frequent indication for late reoperation was by far degeneration of the mitral homograft. However a few cases of infectious endocarditis on the homograft were observed particularly in those patients having been

Table 3. Determinants of structural valve deterioration.

\begin{tabular}{|c|c|c|c|}
\hline Variable & & n (\%) & $P$ value \\
\hline \multirow{2}{*}{ Age } & $<40$ yrs & 21/61 (34.4\%) & \multirow{2}{*}{$\begin{array}{c}\mathrm{p}=0.1 \\
\mathrm{NS}\end{array}$} \\
\hline & $>40$ yrs & 12/58 (20.6\%) & \\
\hline \multirow{2}{*}{ Homograft technique } & Total & 26/79 (32.9\%) & \multirow{2}{*}{$\begin{array}{c}\mathrm{p}=0.08 \\
\mathrm{NS}\end{array}$} \\
\hline & Partial & $7 / 40(17.5 \%)$ & \\
\hline \multirow{2}{*}{ Ring size } & $\leq 30 \mathrm{~mm}$ & 13/49 (26.5\%) & \multirow{2}{*}{$\begin{array}{c}\mathrm{p}=0.3 \\
\mathrm{NS}\end{array}$} \\
\hline & $>30 \mathrm{~mm}$ & 20/57 (35.1\%) & \\
\hline \multirow{2}{*}{ Associated aortic surgery } & YES & $6 / 28(21.4 \%)$ & \multirow{2}{*}{$\begin{array}{c}\mathrm{p}=0.4 \\
\mathrm{NS}\end{array}$} \\
\hline & NO & 27/91 (29.6\%) & \\
\hline \multirow{2}{*}{ Primary endocarditis } & YES & 3/37 (8.1\%) & \multirow{2}{*}{$\mathrm{p}=0.01$} \\
\hline & NO & 30/82 (36.6\%) & \\
\hline \multirow{2}{*}{ Pregnancy } & YES & 6/9 (66.7\%) & \multirow{2}{*}{$\mathrm{p}=0.016$} \\
\hline & NO & 27/97 (27.8\%) & \\
\hline
\end{tabular}



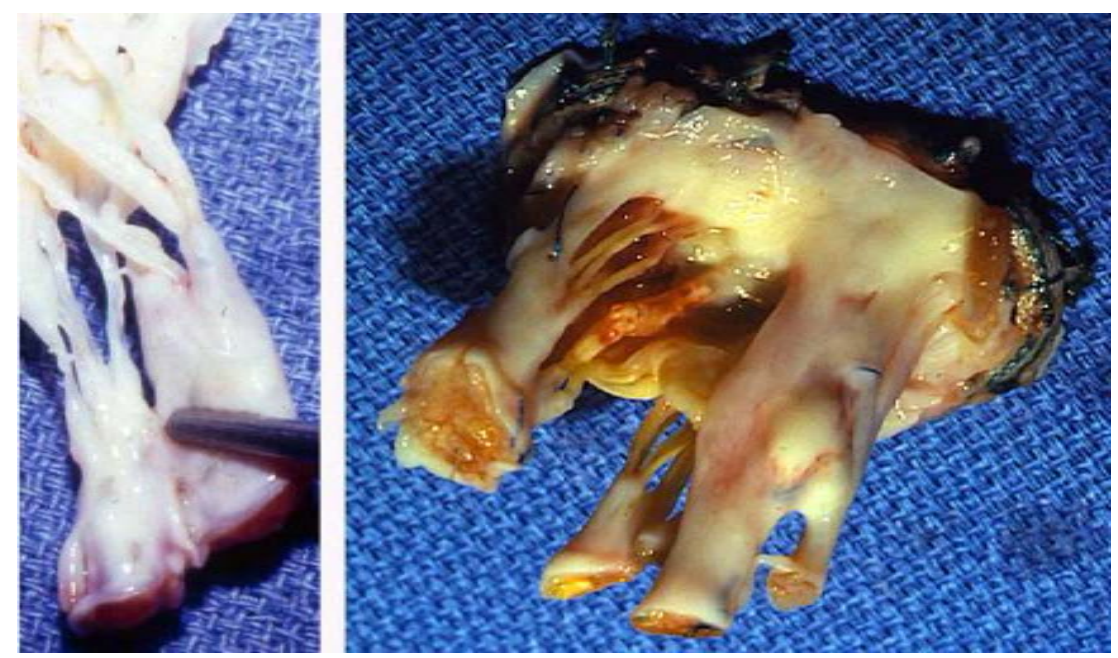

Figure 2. Cryopreserved mitral homograft explant at 14 years: leaflet fibrosis with multiple calcareous nodules. In places, the leaflet tissue is pellucid. Chordae tendinae are markedly thickened particularly at their attachment to the leaflets whereas their proximal part is relatively spared.

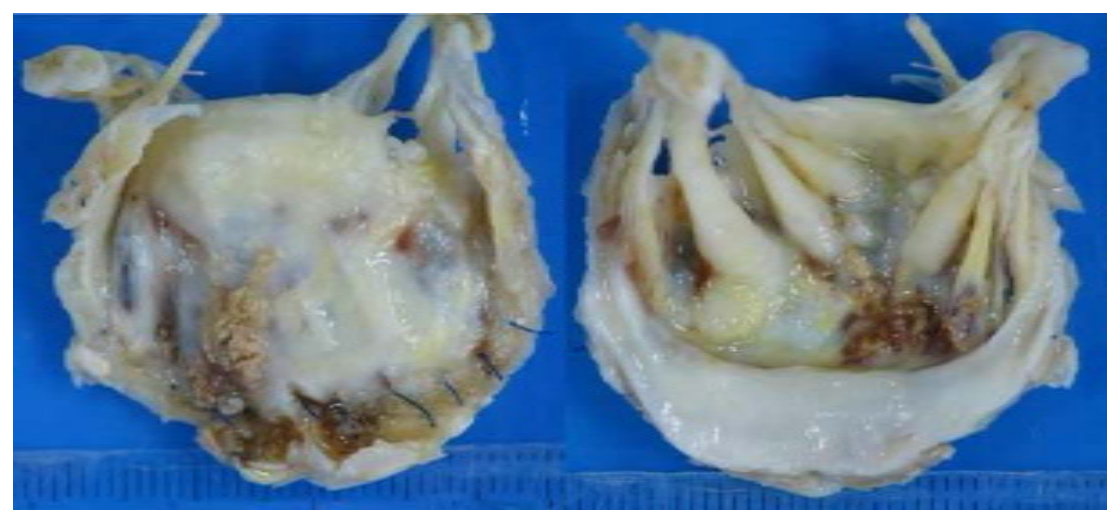

Figure 3. Cryopreserved mitral homograft at 7 years and at 10 years. Left: Complete healing with fibrotic scar of the grafted muscle. The chordae are thin at their attachment to the papillary muscle. Right: Considerable thickening with fusion and calcification of the chordae.

primarily operated for a first episode of endocarditis (ten-fold increased risk). In some cases, reoperation was mainly necessary for aortic valve disease and the mitral homograft which was usually dysfunctioning was replaced at the same time. However in one late reoperation, prophylactic replacement of a normally functioning mitral homograft was performed to obviate the risk of secondary degradation.

Reintervention on mitral homografts was not particularly technically challenging and removal of prosthetic ring as first step during the procedure is recommended. One death in our series was due to technical difficulty in replacing an entirely calcified aortic homograft root. Mortality of reoperation following mitral homograft (8.6\%) did not substantially differ from reported rates for reintervention on bioprostheses [16]. Kaplan Meier freedom from reoperation was $88 \%, 80 \%$ and $64 \%$ at 5 years, 10 years and 15 years respectively. Statistical analysis of reoperation risk factors failed to identify any determinant parameter (Table 1) except for age below 18 years as suggested in previous study [17] and prosthetic ring size $28 \mathrm{~mm}$. Mitral homograft valve function was periodically assessed using echocardiography (Table 2). Interestingly, in the early postoperative period, mitral homograft valve function closely mimicked that of a native valve undergone to repair with annuloplasty (Table 2). In the later period the majority of homografts showed signs of degeneration as leaflet thickening and functional failure resulting in a both leaking and stenotic valve. At the end of the study period we could demonstrate an increase in the mitral regurgitation grade and in the mean transvalvular gradient with a reduction of the valve area 
(Table 2). Interestingly, despite the systolic pulmonary pressures were importantly increased, there was no impact on left ventricle size and function. The diameter of the left atrium remained unchanged throughout the follow-up period, but the prevalence of atrial fibrillation increased. At ten years, one mitral valve homograft out of four was the site of structural deterioration (Figure 1). Although the increased rate of structural deterioration in patients below 40 years of age did not reach statistical significance (Table 3), the stenotic process was clearly accelerated with a higher gradient and lower valve area as compared to older patients (Table 2). Progression towards stenosis is typical of structural deterioration and does not usually exist in endocarditis. Hence it is indisputable that degeneration of mitral homografts occured sooner in younger patients. The same finding has for long been reported for aortic homografts [18] and for bioprostheses [16].

Total homografts showed more frequent and marked structural valve deterioration than in partial replacements (Table 2 and Table 3). Explanations underlying this evidence might be found in the faster deterioration of the cryopreserved homologous valvular tissue compared to the remnants of the native valve in partial homografts. In case of a hemi-valve replacement, fibro-calcareous involvement of the partial homograft was commonly observed whereas the opposite commissural area made from native tissue was healthy and opened widely in diastole. The lower incidence of structural deterioration in patients with endocarditis was probably related to the preferential use of partial homograft in this subgroup.

In women of childbearing age, the choice of a mitral homograft as valve substitute was thought to be appropriate. The lack of oral anticoagulation clearly facilitated normal pregnancies in this series. As the reverse of the coin, two thirds of women having experienced pregnancy developed structural deterioration of the mitral homograft thereafter (Table 3). Interestingly, the only two variables determining SVD in this population were represented by endocarditis etiology and pregnancy. While endocarditis is a widely known risk factor for SVD, the role of pregnancy is controversial in the literature [19]. Some studies showed a significant association with SVD and need for reoperation [20] [21], while recent studies indicate no effect on the acceleration of prosthesis degeneration [22] [23]. It has been suggested that the high calcium turnover during pregnancy is the cause for the accelerated degeneration of bioprostheses [24] [25] unveiling a potential pathogenetic link between pregnancy and SVD. However, the majority of the studies which do not support this theory involved the use of bioprosthesis and not of crypreserved homografts. Considering our data, it could be speculated that the different method of preservation or the intrinsic characteristics of the homografts might determine a greater susceptibility to degeneration during pregnancy.

The same trend has been reported for bioprostheses [26]. In this study, diagnosis of structural deterioration relied not only on the aspect of the valve at reoperation; patients with gross leaflet thickening or calcification together with severe dysfunction on follow-up echocardiography were considered as well [7]. Collectively freedom from structural deterioration of the mitral homograft was $76 \%$ at 10 years. Jamieson et al. reported a freedom from structural deterioration of mitral bioprostheses of $60 \%$ and $80 \%$ for pericardial bioprostheses at 10 years in patients aged less than 40 years [16]. Others have reported lower freedom from structural deterioration rates for the same age range [26]. However, in those studies, only structural valve deterioration noted at reoperation was considered (no inclusion on echocardiography criteria). Thus, the structural deterioration rate of mitral homografts appears comparable with that of the best existing biological valve substitutes. We previously published the long-term follow-up of a 106 patient series treated with mitral homograft showing optimal clinical results [27]. Nevertheless because the implantation technique of the mitral homograft is more challenging and carries a risk of early failure, which does not exist with bioprostheses, its use cannot be recommended until a more prolonged durability can reasonably be expected. In our own practice over the past decade mitral homografts have seldom been used whenever biological mitral valve replacement was needed and bioprostheses were preferred. However, from the results of the current study designed to evaluate the long-term outcomes in a subset of patients receiving a double homograft in the context of complex valve endocarditis, we believe that this strategy could be a feasible and effective approach when infective involvement of mitro-aortic continuity occurs.

Pathological findings (Figures 2-3) on mitral homografts explanted for degeneration are in agreement with observations reported for aortic homografts [28]. Valve tissue was shown to be invaded by a dense fibrosis with a complete loss of the normal trilaminar architecture and scattered with calcium deposits. Except for one early explant in a child which was the site of a severe inflammatory reaction, the homograft tissue was virtually acellular with no sign of immune mediated injury. These observations suggest that the actual cryopreservation process used for storing valvular homografts profoundly alters cellular components of the endothelium and of the collagen matrix. As opposed to the proponents of the immune induced degeneration theory, we believe that 
cell viability is an essential prerequisite for valve tissue regeneration. Future direction in order to extend the longevity of mitral homografts would call for an improvement in the cryopresevation method (temperature, type and concentration of cryoprotective agents...). Alternatively, as suggested by the remarkable lack of valve deterioration in heart transplant recipients [29], the use of ultra-fresh homografts inserted within 24 hours following harvesting could be advocated.

\section{Conclusion}

In conclusion, double cryopreserved homograft implantation for infective endocarditis might be an effective strategy especially if the mitro-aortic curtain is involved [8] [9]. However, a particular attention should be paid to in women in childbearing age because pregnancy might accelerate structural degeneration of the cryopreserved homografts. Further basic science investigations are required to elucidate the mechanisms underlying this find- ing and clinical postoperative large-scale follow-up studies should be advocated to perceive the effective signi- ficance of pregnancy in heart valve surgery.

\section{Limitations}

Among the limitations of this study authors acknowledge that mitral homografting is a surgical procedure for non-systematic application. The technique of implantation of the papillary muscle in the ventricle may present technical difficulties. Alternatively, valve replacement with biological prosthesis has currently a great durability and still remains recommended in cardiac surgery centers where the experience of this technique is not optimal. We believe that homograft replacement of the mitral valve could be the preferred technique in complex valve endocarditis when the mitro-aortic junction is compromised.

\section{References}

[1] Sievers, H.H., Lange, P.E., Yankah, A.C., Wessel, A. and Bernhard, A. (1985) Allogeneous Transplantation of the Mitral Valve. An Open Question. The Thoracic and Cardiovascular Surgeon, 33, 227-229. http://dx.doi.org/10.1055/s-2007-1014126

[2] Kumar, A.S. and Trehan H. (1994) Homograft Mitral Valve Replacement-A Case Report. The Journal of Heart Valve Disease, 3, 473-475.

[3] Acar, C., Farge, A., Ramsheyi, A., Chachques, J.C., Mihaileanu, S., Gouezo, R., Gerota, J. and Carpentier, A.F. (1994) Mitral Valve Replacement Using a Cryopreserved Mitral Homograft. The Annals of Thoracic Surgery, 57, 746-748. http://dx.doi.org/10.1016/0003-4975(94)90582-7

[4] Acar, C., Tolan, M., Berrebi, A., Gaer, J., Gouezo, R., Marchix, T., Gerota, J., Chauvaud, S., Fabiani, J.N., Deloche, A. and Carpentier, A. (1996) Homograft Replacement of the Mitral Valve. Graft Selection, Technique of Implantation, and Results in Forty-Three Patients. The Journal of Thoracic and Cardiovascular Surgery, 111, 367-380. http://dx.doi.org/10.1016/S0022-5223(96)70446-4

[5] Ali, M., Iung, B., Lansac, E., Bruneval, P. and Acar, C. (2004) Homograft Replacement of the Mitral Valve: EightYear Results. The Journal of Thoracic and Cardiovascular Surgery, 128, 529-534. http://dx.doi.org/10.1016/j.jtcvs.2003.11.076

[6] Doty, D.B. and Acar, C. (1998) Mitral Valve Replacement with Homograft. The Annals of Thoracic Surgery, 66, 2127-2131. http://dx.doi.org/10.1016/S0003-4975(98)01089-3

[7] Akins, C.W., Miller, D.C., Turina, M.I., Kouchoukos, N.T., Blackstone, E.H., Grunkemeier, G.L., Takkenberg, J.J., David, T.E., Butchart, E.G., Adams, D.H., Shahian, D.M., Hagl, S., Mayer, J.E. and Lytle, B.W. (2008) Guidelines for Reporting Mortality and Morbidity after Cardiac Valve Interventions. The Journal of Thoracic and Cardiovascular Surgery, 135, 732-738. http://dx.doi.org/10.1016/j.jtcvs.2007.12.002

[8] Amado-Cattaneo, R. (1998) Combined Mitral and Aortic Homograft Valve Replacement for Acute Bacterial Endocarditis. Ann Thorac Surg, 66, 267-268. http://dx.doi.org/10.1016/S0003-4975(98)00406-8

[9] Reardon, M.J., Vinnerkvist, A. and LeMaire, S.A. (1999) Mitral Valve Homograft for Mitral Valve Replacement in Acute Bacterial Endocarditis. The Journal of Heart Valve Disease, 8, 71-73.

[10] Plunkett, M.D., Schneider, D.J., Shah, J.J., Bash, S.E., Bond, L.M. and Geiss, D.M. (1998) Homograft Replacement of Mitral Valve in Children. The Annals of Thoracic Surgery, 66, 849-852. http://dx.doi.org/10.1016/S0003-4975(98)00645-6

[11] Doty, D.B., Flores, J.H., Doty, J.R. and Millar, R.C. (1999) Mitral Valve Replacement with Homograft. Seminars in 
Thoracic and Cardiovascular Surgery, 11, 191-193.

[12] Gulbins, H., Kreuzer, E., Uhlig, A. and Reichart, B. (2000) Mitral Valve Surgery Utilizing Homografts: Early Results. The Journal of Heart Valve Disease, 9, 222-229.

[13] Yankah, A.C., Sievers, H.H., Lange, P.E. and Bernhard, A. (1995) Clinical Report on Stentless mitral Allografts. The Journal of Heart Valve Disease, 4, 40-44.

[14] Kumar, A.S., Choudhary, S.K., Mathur, A., Saxena, A., Roy, R. and Chopra, P. (2000) Homograft Mitral Valve Replacement: Five Years' Results. The Journal of Thoracic and Cardiovascular Surgery, 120, 450-458. http://dx.doi.org/10.1067/mtc.2000.107829

[15] Gulbins, H., Anderson, I., Kilian, E., Schrepfer, S., Uhlig, A., Kreuzer, E. and Reichart, B. (2002) Five Years of Experience with Mitral Valve Homografts. The Thoracic and Cardiovascular Surgeon, 50, 223-229. http://dx.doi.org/10.1055/s-2002-33094

[16] Jamieson, W.R.E., Marchand, M.A., Pelletier, C.L., Norton, R., Pellerin, M., Dubiel, T.W., Aupart, M.R., Daenen, W.J., Holden, M.P., David, T.E., Ryba, E.A. and Anderson Jr., W.N. (1999) Structural Valve Deterioration in Mitral Replacement Surgery: Comparison of Carpentier-Edwards Supra-Annular Porcine and Perimount Pericardial Bioprostheses. Journal of Thoracic and Cardiovascular Surgery, 118, 297-305. http://dx.doi.org/10.1016/S0022-5223(99)70220-5

[17] Chauvaud, S., Waldmann, T., d’Attellis, N., Bruneval, P., Acar, C., Gerota, J., Jarraya, M. and Carpentier, A. (2003) Homograft Replacement of the Mitral Valve in Young Recipients: Mid-Term Results. European Journal Cardio-Thoracic Surgery, 23, 560-566. http://dx.doi.org/10.1016/S1010-7940(03)00003-4

[18] O’Brien, M.F., Harrocks, S., Stafford, E.G., Gardner, M.A., Pohlner, P.G., Tesar, P.J. and Stephens, F. (2001) The Homograft Aortic Valve: A 29-Year, 99.3\% Follow up of 1,022 Valve Replacements. Journal of Heart Valve Disease, 10, 334-344.

[19] Hung, L. and Rahimtoola, S.H. (2003) Prosthetic Heart Valves and Pregnancy. Circulation, 107, 1240-1246.

[20] Hanania, G., Thomas, D., Michel, P.L., Garbarz, E., Age, C., Millaire, A. and Acar, J. (1994) Pregnancy and Prosthetic Heart Valves: A French Cooperative Retrospective Study of 155 Cases. European Heart Journal, 15, 1651-1658.

[21] Badduke, B.R., Jamieson, W.R., Miyagishima, R.T., Munro, A.I., Gerein, A.N., MacNab, J. and Tyers, G.F. (1991) Pregnancy and Childbearing in a Population with Biologic Valvular Prostheses. Journal of Thoracic and Cardiovascular Surgery, 102, 179-186.

[22] Nishida, H., Takahara, Y., Takeuchi, S., Mogi, K. and Murayama, H. (2005) Long-Term Evaluation of Bovine Pericardial Bioprostheses in Young Women: Influence of Pregnancy. Japanese Journal of Thoracic and Cardiovascular Surgery, 53, 557-561. http://dx.doi.org/10.1007/s11748-005-0067-x

[23] Cleuziou, J., Hörer, J., Kaemmerer, H., Teodorowicz, A., Kasnar-Samprec, J., Schreiber, C. and Lange, R. (2010) Pregnancy Does Not Accelerate Biological Valve Degeneration. International Journal of Cardiology, 145, 418-421. http://dx.doi.org/10.1016/j.ijcard.2010.04.095

[24] Sbarouni, E. and Oakley, C.M. (1994) Outcome of Pregnancy in Women with Valve Prostheses. British Heart Journal, 71, 196-201. http://dx.doi.org/10.1136/hrt.71.2.196

[25] Jamieson, W.R., Miller, D.C., Akins, C.W., Munro, A.I., Glower, D.D., Moore, K.A. and Henderson, C. (1995) Pregnancy and Bioprostheses: Influence on Structural Valve Deterioration. Annals of Thoracic Surgery, 60, S282-S286. http://dx.doi.org/10.1016/0003-4975(95)00308-8

[26] Tanaka, H., Okita, Y., Kasegawa, H., Takamoto, S., Tabayashi, K., Yagihara, T., Ueda, Y., Aoyagi, S., Komeda, M., Eishi, K. and Kurosawa, H. (2010) The Fate of Bioprostheses in Middle-Aged Patients: The Japanese Experience. Journal of Heart Valve Disease, 19, 561-567.

[27] Olivito, S., Lalande, S., Nappi, F., Hammoudi, N., D’Alessandro, C., Fouret, P. and Acar, C. (2012) Structural Deterioration of the Cryopreserved Mitral Homograft Valve. Journal of Thoracic and Cardiovascular Surgery, 144, 313320. http://dx.doi.org/10.1016/j.jtcvs.2011.06.041

[28] Koolbergen, D.R., Hazekamp, M.G., de Heer, E., Bruggemans, E.F., Huysmans, H.A., Dion, R.A. and Bruijn, J.A. (2002) The Pathology of Fresh and Cryopreserved Homograft Heart Valves: An Analysis of Forty Explanted Homograft Valves. Journal of Thoracic and Cardiovascular Surgery, 124, 689-697. http://dx.doi.org/10.1067/mtc.2002.124514

[29] Wilhelmi, M.H., Bara, C., Kofidis, T., Wilhelmi, M., Pichlmaier, M. and Haverich, A. (2006) Long-Term Cardiac Allograft Valves after Heart Transplant Are Functionally and Structurally Preserved, in Contrast to Homografts and Bioprostheses. Journal of Heart Valve Disease, 15, 777-782. 